\title{
Minimally Invasive Surgery for Osteoid Osteoma of the Cervical Spine Using Microendoscopic Discectomy System
}

\author{
Yukako Nakamura, Shoji Yabuki, Shin-Ichi Kikuchi, Shin-Ichi Konno \\ Department of Orthopaedic Surgery, Fukushima Medical University School of Medicine, Fukushima, Japan
}

\begin{abstract}
We report herein the case of an 18-year-old man who underwent endoscopic resection for an osteoid osteoma in the seventh cervical facet joint. The patient had experienced right neck pain for approximately one year, but no neurological abnormalities were noted. Cervical magnetic resonance imaging suggested an osteoid osteoma in the superior articular process of the seventh cervical vertebra. The tumor was resected microendoscopically. Operative time was 1 hour 29 minutes, and blood loss was $5 \mathrm{~mL}$. During the two years since surgery, the patient has remained pain free with no cervical spine instability. We thus propose microendoscopic surgery for osteoid osteoma developing in a posterior element of the cervical spine is a potentially effective operative procedure.
\end{abstract}

Keywords: Endoscopic surgery; Osteoid osteoma; Cervical spine

\section{Introduction}

Spinal endoscopic surgery is mainly performed for lumbar spine disorders. We have applied microendoscopic surgery techniques for cervical spine diseases, and found that they can be used safely with low invasiveness in degenerative cervical spinal diseases [1-4]. This study reports on a patient with osteoid osteoma of the cervical spine, for which the traditional treatment is surgical tumor resection. Recently, percutaneous radiofrequency ablation [5], percutaneous computed tomography (CT)guided resection [6,7], and curettage using a navigation system [8] have been described as minimally invasive treatments. In the present case, we performed microendoscopic resection of an osteoid osteoma affecting the cervical facet joint, through which we were able to resect the tumor safely with low invasiveness.

\section{Case Report}

The patient was an 18-year-old man who complained of right neck pain. Pain from the right neck to the back had been present for one year prior to his initial visit to our hospital. He had consulted another doctor approximately eleven months previously. No abnormalities were seen through plain radiography, and symptoms were alleviated by administration of a non-steroidal anti-inflammatory drug (NSAID). When the NSAID was discontinued six months later, symptoms recurred. Based on CT and magnetic resonance imaging (MRI), an osteoid osteoma in the superior articular process of C7 was suspected and the patient was referred to our hospital for surgery. There was tenderness at the paraspinal muscles of the right neck. Flexion and extension of the cervical spine exacerbated the right neck pain. No neurological abnormalities

Received Oct 11, 2011; Revised Dec 9, 2011; Accepted Jan 26, 2012

Corresponding author: Yukako Nakamura

Department of Orthopaedic Surgery, Fukushima Medical University School of Medicine,

1 Hikarigaoka, Fukushima, 960-1295, Japan

Tel: +81-(0)24-547-1276, Fax: +81-(0)24-548-5505, E-mail: chillan1996@yahoo.co.jp 
were noted, nor were there any abnormal blood test findings. Alignment also appeared normal on a plain cervical radiograph, and there were no obvious abnormalities. Upon closer inspection, however, indistinct lucency of the bone was observed in the right C6/7 facet joint (Fig. 1). On the plain CT scan, a nidus was seen in the right superior articular process of $\mathrm{C} 7$ (Fig. 2). On the contrast MRI, there were signal changes in the right superior articular process of $\mathrm{C}$, and a conspicuous contrast effect was seen in the surrounding tissue (Fig. 3). Osteoid osteoma of

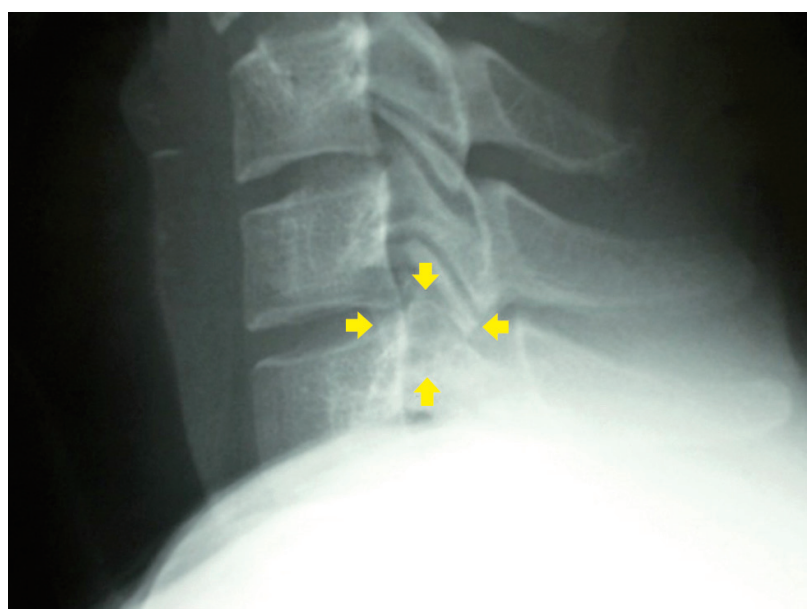

Fig. 1. Lateral view (enlarged) of plain radiographs (initial examination). Alignment is good, and no obvious abnormalities are seen. Closer inspection, however, reveals indistinct lucency of the bone in the right C6/7 facet joint (arrows).

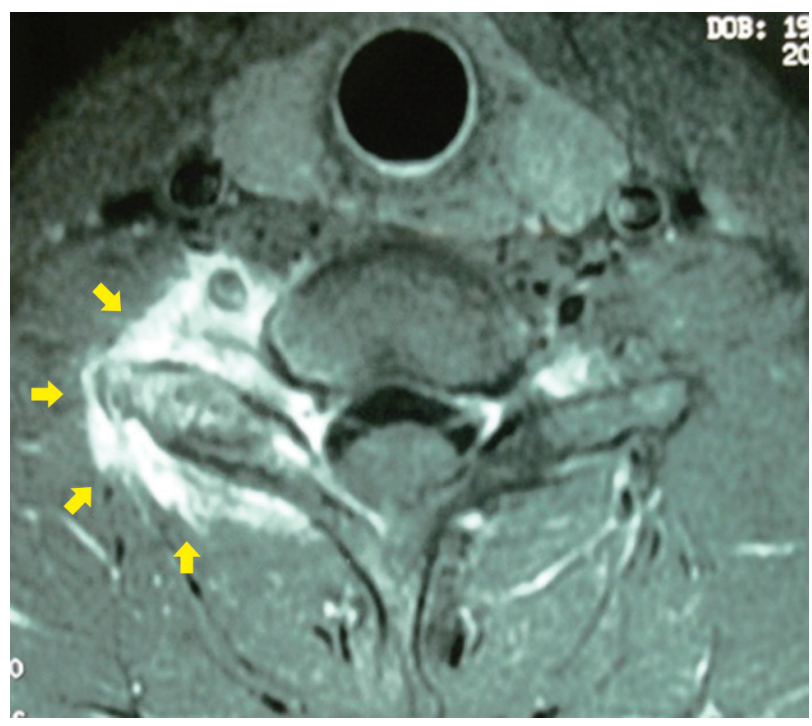

Fig. 3. Axial view of cervical contrast magnetic resonance imaging. There is intensity change (arrows) in the right superior articular process of C7, and a conspicuous contrast effect is seen at the surrounding tissue. the right superior articular process of C7 was diagnosed based on these findings.

Microendoscopic surgery using a tubular retractor (METRx System Medtronic Sofamor Danek, Co., Ltd., Minneapolis, MN, USA) was selected because of its low invasiveness. A $2-\mathrm{cm}$ incision was made $2 \mathrm{~cm}$ to the right of the midline, and an $18-\mathrm{mm}$ in diameter tubular retrac-

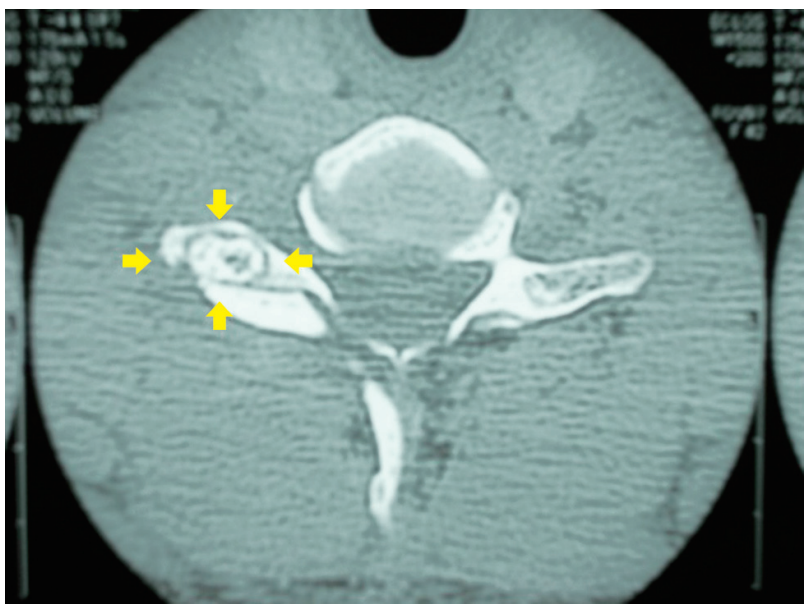

Fig. 2. Cervical spine computed tomography. Bone lucency, thought to be a nidus, is seen in the right superior articular process of C7 (arrows).

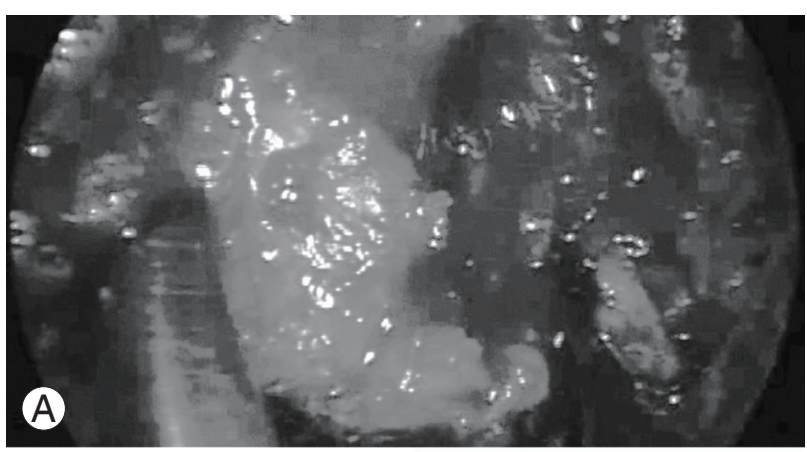

(B)
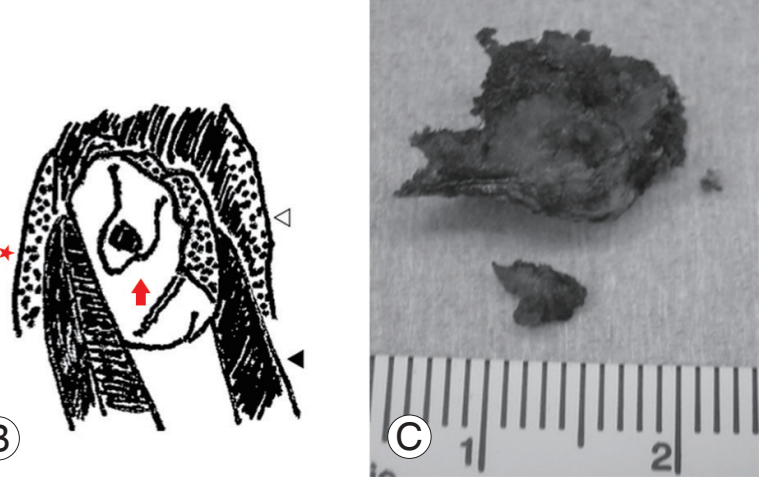

Fig. 4. Photograph and illustration of surgery and excised tumor. (A) Endoscopic view. (B) Illustration. (C) Excised tumor (arrow). After excision of the C6 inferior articular process $(\star)$, osteoid osteoma $(\uparrow)$ in the $C 7$ superior articular process $(\triangle)$ was removed using forceps $(\boldsymbol{\Delta})$. 
tor was placed. After coagulation of the soft tissue, the right C6/7 facet joint was exposed. After excision of the C6 inferior articular process, the C7 superior articular process was removed using a chisel and rongeurs. Right C6/7 total facetectomy was performed. The right C7 nerve root could be confirmed when the $\mathrm{C} 7$ superior articular process was completely excised to the lateral side

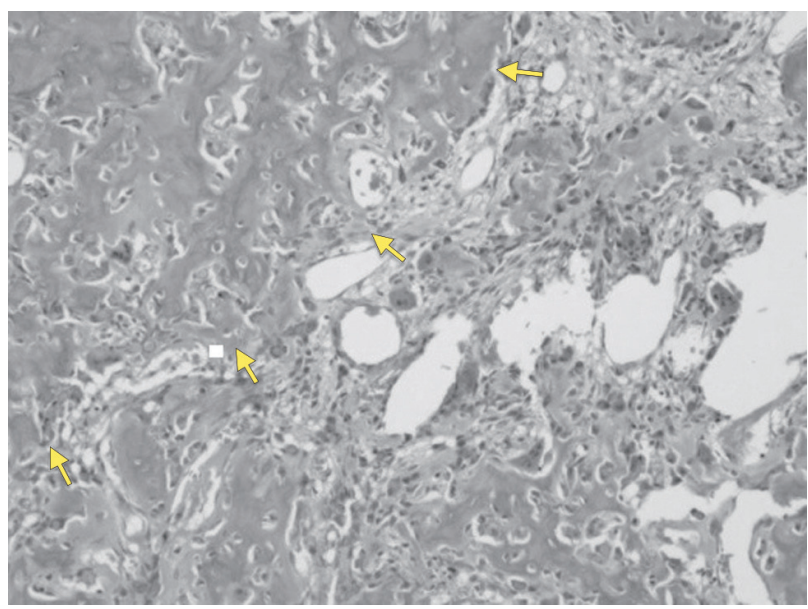

Fig. 5. Photo of pathological tissue. An osteoid formation (arrows) covered with osteoblasts is seen $(H \& E, \times 400)$.
(Fig. 4). The operative time was 1 hour 29 minutes, and estimated blood loss was $5 \mathrm{~mL}$. Pathologically, an osteoid formation covered with osteoblasts was seen. The pathological diagnosis was thus osteoid osteoma (Fig. 5).

On postoperative plain radiographs, the right $\mathrm{C} 6 / 7$ facet joint was completely resected (Fig. 6). No changes

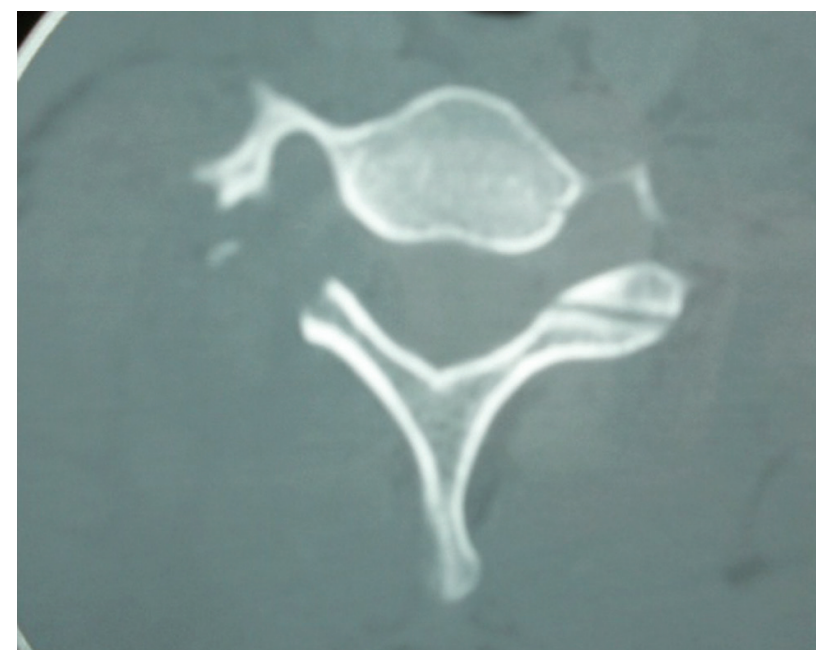

Fig. 7. Cervical spine computed tomography (postoperative). Right C6/7 facet joint is resected, and no tumor is confirmed.
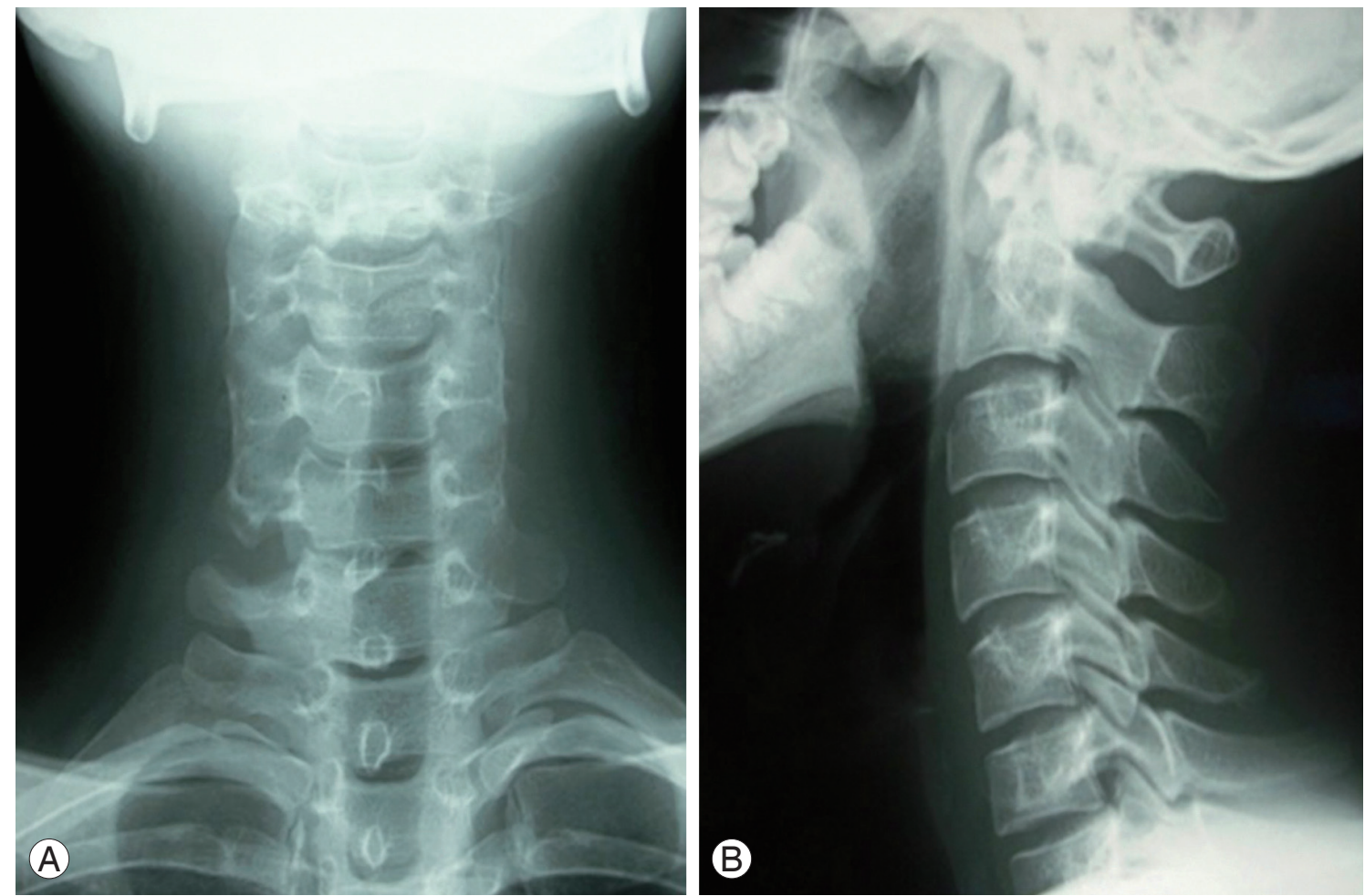

Fig. 6. Plain radiograph (postoperative). (A) Anteroposterior view. (B) Lateral view. Right C6/7 facet joint is resected. No alignment changes are seen. 
in alignment were detected. Postoperative CT confirmed complete resection of the tumor (Fig. 7). Postoperative MRI also showed that the tumor had been completely resected (Fig. 8). At 28 months after surgery, there had been no recurrence of symptoms. There was mild spondylolisthesis on C6/7. However, spinal instability such as increase of spondylolisthesis and/or posterior widening were not seen in the flexion-extension radiographs.

\section{Discussion}

Osteoid osteoma is a benign bone tumor first described by Jaffe [9] in 1935. It frequently occurs in the long bones of young men, causing severe pain in the affected area. On radiographs, osteoid osteoma is characterized by an area of lucency, a nidus, that is broadly surrounded by sclerotic bone [10]. Using data from the national registry of bone tumor patients (1972 to 1995), the incidence of osteoid osteoma in the spine is low, accounting for 47 (6.1\%) of the 765 cases [11]. Among these cases, the tumor commonly occurred in posterior elements, such as the lamina, facet joint or pedicle [12-15].

We have previously reported endoscopic surgery for patients with degenerative cervical spine diseases [1-4]. There have, however, been no reports on endoscopic surgery for treating osteoid osteoma. We performed endoscopic resection of an osteoid osteoma in a cervical facet joint.

Kim et al. [16] described the key concepts of minimally invasive spine surgery: 1) avoidance of muscle crush injury by self-retaining retractors, 2) no disruption of the tendon attachment sites of key muscles, particularly the origin of the multifidus muscle at the spinous process,

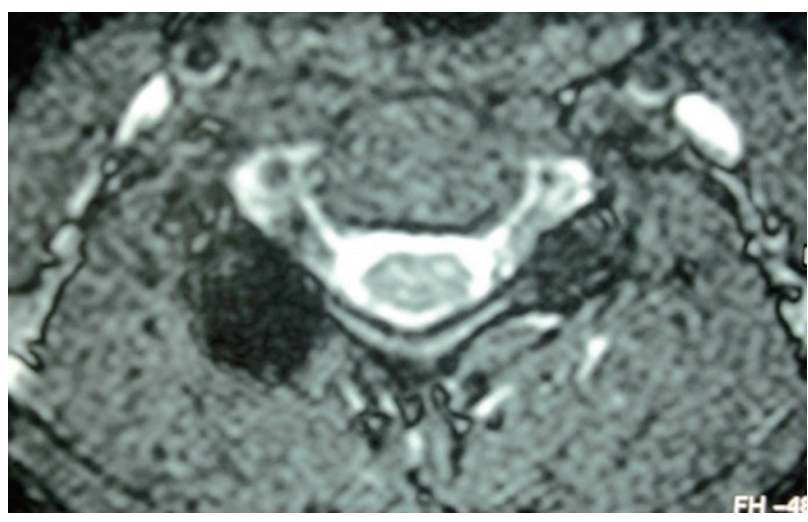

Fig. 8. Cervical spine magnetic resonance imaging, axial view (postoperative). The tumor is completely resected.
3) utilization of known anatomic neurovascular and muscle compartment planes, and 4) a minimization of collateral soft tissue injury by limiting the width of the surgical corridor. This study also pointed out that one of the main goals of minimally invasive spine surgery is to reduce trauma to the posterior paraspinal muscles [16]. Although we performed C6/7 total facetectomy, we could reduce trauma to the posterior paraspinal muscles and collateral soft tissue injury in the present case by using an endoscopic technique. However there is a disadvantage to endscopic surgery in that incomplete resection of the tumor may occur. Although microendoscopy magnifies the tumor, there is a possibility that the whole tumor is not seen. Incomplete resection may thus cause recurrence of the tumor $[17,18]$.

It has been reported that increased annulus stresses and segmental instability may occur when bilateral facet resection exceeds 50\% [19]. We performed total unilateral facet resection. Since the patient was only 18 years old, long-term follow-up observation will be necessary to monitor the potential appearance of cervical spine instability and to judge the necessity of instrumentation and fusion surgery.

\section{Conflict of Interest}

No potential conflict of interest relevant to this article was reported.

\section{References}

1. Yabuki S, Kikuchi S, Sato K. Microendoscopic foraminotomy for cervical spondylotic radiculopathy:a case report. Seikei Geka 2002;53:1200-1.

2. Yabuki S, Kikuchi S. Endoscopic partial laminectomy for cervical myelopathy. J Neurosurg Spine 2005;2:170-4.

3. Yabuki S, Kikuchi S. Endoscopic surgery for cervical myelopathy due to calcification of the ligamentum flavum. J Spinal Disord Tech 2008;21:518-23.

4. Yabuki S, Otani K, Nikaido T, Kikuchi S. Endoscopic surgery for degenerative cervical spine disease. J Jpn Soc Spine Surg Relat Res 2008;19:539-42.

5. Rosenthal DI, Springfield DS, Gebhardt MC, Rosenberg AE, Mankin HJ. Osteoid osteoma: percutaneous radio-frequency ablation. Radiology 1995;197:451-4.

6. Shinozaki T, Sato J, Watanabe H, et al. Osteoid os- 
teoma treated with computed tomography-guided percutaneous radiofrequency ablation: a case series. J Orthop Surg (Hong Kong) 2005;13:317-22.

7. Voto SJ, Cook AJ, Weiner DS, Ewing JW, Arrington LE. Treatment of osteoid osteoma by computed tomography guided excision in the pediatric patient. J Pediatr Orthop 1990;10:510-3.

8. Nagashima H, Nishi T, Yamane K, Tanida A. Case report: osteoid osteoma of the $\mathrm{C} 2$ pedicle: surgical technique using a navigation system. Clin Orthop Relat Res 2010;468:283-8.

9. Jaffe HL. "Osteoid-osteoma": a benign osteoblastic tumor composed of osteoid and atypical bone. Arch Surg 1935;31:709-28.

10. Canale ST, Beaty JH. Campbell's operative orthopaedics. Tokyo: Elsevier Japan KK; 2004.

11. A musculoskeletal tumor committee in the Japanese orthopaedic association. A list of bone tumor patients in Japan (1994). Tokyo: National Cancer Center; 1995.

12. Ochi K, Yabe H, Morioka H, et al. Osteoid osteoms of the spine: a report of four cases. Seikei Geka 2001;52:535-638.

13. Kawahara C, Tanaka Y, Kato H, Watanabe S,
Kokubun S. Myolysis of the erector spinae muscles as the cause of scoliosis in osteoid osteoma of the spine. Spine (Phila Pa 1976) 2002;27:E313-5.

14. Kubo M, Kawano O, Shiba K, Tsuneyoshi M, Matono $\mathrm{H}$. Osteoid osteoma of pedicle of seventh cervical spine: a case report. Orthop Traumatol 2007;56:65-8.

15. Morioka H, Nakagawa T, Ichimura S. A case of osteoid osteoma of the lamina of the seventh cervical spine. Seikei Geka 1998;44:935-7.

16. Kim CW, Siemionow K, Anderson DG, Phillips FM. The current state of minimally invasive spine surgery. Instr Course Lect. 2011;60:353-70.

17. Gasbarrini A, Cappuccio M, Bandiera S, Amendola L, van Urk P, Boriani S. Osteoid osteoma of the mobile spine: surgical outcomes in 81 patients. Spine (Phila Pa 1976) 2011;36:2089-93.

18. Haji FA, Cenic A, Crevier L, Murty N, Reddy K. Minimally invasive approach for the resection of spinal neoplasm. Spine (Phila Pa 1976) 2011;36:E101826.

19. Voo LM, Kumaresan S, Yoganandan N, Pintar FA, Cusick JF. Finite element analysis of cervical facetectomy. Spine (Phila Pa 1976) 1997;22:964-9. 